\title{
Latin American Expert Consensus for Comprehensive Management of Type 2 Diabetes from a Metabolic- Cardio-Renal Perspective for the Primary Care Physician
}

\author{
Roopa Mehta (D) - Daniel Pichel · Chih Hao Chen-Ku • \\ Pablo Raffaele · Antonio Méndez Durán · Francisco Padilla • \\ Jose Javier Arango Alvarez · José Esteban Costa Gil · Juan Esteban Gómez Mesa • \\ Mariano Giorgi · Rodolfo Lahsen · Andrei C. Sposito
}

Received: September 16, 2020 / Accepted: October 27, 2020 / Published online: December 15, 2020

(C) The Author(s) 2020

\section{ABSTRACT}

Growing scientific evidence from studies on type 2 diabetes (T2D) has recently led to a better understanding of the associated metabolic-cardio-renal risks. The large amount of available information makes it essential to have a

R. Mehta $(\bowtie)$

Metabolic Diseases Research Unit (UIEM), National Institute of Medical Sciences and Nutrition Salvador Zubirán (INCMNSZ), Vasco De Quiroga 15, Belisario Dominguez, Tlalpan 14200, Mexico

e-mail: roopamehta@yahoo.com

D. Pichel

Department of Medicine/Cardiology, Hospital Paitilla, Calle 53, Ave Balboa, Urb. Marbella, Panama City 00134, Panama

C. H. Chen-Ku

Clínica Los Yoses, San Pedro Montes de Oca, San José, Costa Rica

\section{P. Raffaele}

Department of Nephrology, Fundación Favaloro University Hospital, Buenos Aires 1093, Argentina

A. Méndez Durán

Coordinacion de Planeacion de Infraestructura Medica, Instituto Mexicano del Seguro Social, C.P. 6700, Mexico City, Mexico

F. Padilla

Cardiología Clínica e Intervencionista, 44670

Guadalajara, Jalisco, Mexico practical guide that summarizes the recommendations for the initial management of patients with T2D, integrating different aspects of endocrinology, cardiology, and nephrology. The expert consensus presented here does not attempt to summarize all the evidence in this regard but rather attempts to define practical summary recommendations for the primary

\section{J. J. Arango Alvarez}

Clinica del Café, Armenia, Quindio, Colombia

J. Esteban Costa Gil

Instituto de Cardiología y Cirugía Cardiovascular, Buenos Aires, Argentina

\section{J. Esteban Gómez Mesa}

Internal Medicine/Cardiology, Fundación Valle del Lili, Cali 760026, Colombia

\section{Giorgi}

Cardiology Section, Cardiovascular Prevention Unit, CEMIC, Buenos Aires, Argentina

\section{R. Lahsen}

Centro de Diabetes Adultos, Clinica Las Condes, 7591047 Santiago, Chile

\section{A. C. Sposito}

Department of Cardiology, State University of Campinas (Unicamp), Campinas, Brazil 
care physician to improve the clinical prognosis and management of patients with T2D, while ensuring economic sustainability of health systems, beyond glycemic control.

Keywords: Antidiabetic drugs; Cardiovascular disease; Heart failure; Hypoglycemia; Type 2 diabetes mellitus

\section{Key Summary Points}

\section{Background}

Recent reports indicate that the disease and economic burden of type 2 diabetes (T2D) is increasing steadily in the Latin American region.

Primary care physicians (PCPs), who in most cases diagnose and manage patients with T2D, face multifactorial challenges that hinder translating the guidelines, which are often developed by specialists.

PCPs also face patient-specific barriers, such as social influences, perceptions and beliefs, education and lifestyle, patient compliance, paternalistic attitude, vertical communication, and lack of support related to diet at home, while managing patients with T2D.

In this regard, the consensus document presented here provides the following recommendations (from the metabolic-cardio-renal perspective) to PCPs from Latin American region:

\section{Recommendations}

At the first visit, it is recommended to confirm the diagnosis of diabetes and evaluate the metabolic-cardio-renal baseline status through measurement of glycosylated hemoglobin (HbA1c), lowdensity lipoprotein cholesterol (LDL-C), blood pressure (BP), microalbuminuria, estimated glomerular filtration rate (eGFR), and renal hyperfiltration.
Next, it is important to set $\mathrm{HbA1c}$, BP and LDL-C targets that may vary depending on the patient's history (duration of diabetes, cardiovascular [CV] disease, other $\mathrm{CV}$ risk factors, renal status, and other comorbidities).

Management of each risk factor (metabolic, cardiac, and renal) includes:

Patient counseling on the asymptomatic and progressive nature of the disease, importance of the need to check blood sugar regularly despite being on treatment, treatment adherence, and continuous glucose monitoring.

Pharmacological treatment for each risk factor: angiotensin-converting-enzyme inhibitors/angiotensin II receptor blockers [ACEI/ARB]) for BP; statins for LDL-C; sodium-glucose co-transporter-2 inhibitors for renal hyperfiltration; ACEI/ ARB for microalbuminuria/hypertension; close monitoring of potassium, creatinine levels and GFR.

Consultation with a specialist (diabetologist, cardiologist, and nephrologist) when required.

Other general recommendations for glycemic control include balanced isocaloric diet comprising all nutrients, moderate to vigorous physical activity, smoking cessation, and cautious use of antiplatelet drugs (dual therapy with aspirin and clopidogrel).

\section{DIGITAL FEATURES}

This article is published with digital features, including a summary slide, to facilitate understanding of the article. To view digital features for this article go to https://doi.org/10.6084/ m9.figshare.13142708. 


\section{INTRODUCTION}

According to International Diabetes Federation (IDF) estimates, there were globally 463 million people with diabetes in 2019 (9.3\% of all adults worldwide aged 20-79 years). By 2045, it is estimated that 700 million people will be affected, an increase of $51 \%$ in 26 years. The mortality rate due to diabetes is estimated to be $11.3 \%$ worldwide, with $46.2 \%$ of these deaths occurring in people aged $<60$ years [1]. The total diabetes-related health expenditure in 2019 (USD 760 billion) increased by $4.5 \%$ compared to 2017 (USD 727 billion) for adults aged 20-79 years and is projected to increase $11.2 \%$ by 2045 [1].

More than $90 \%$ of patients with type 2 diabetes (T2D) report micro- and macrovascular complications, such as retinopathy, nephropathy, neuropathy, and cardiovascular diseases (CVD), resulting in significant physical and psychological distress and imposing a greater burden on healthcare systems [2]. The IDF estimated that approximately 4.2 million adults died because of diabetes and its complications in 2019 , which is equivalent to one death every $8 \mathrm{~s}$ [1]. Atherosclerotic events remain the most important driver of mortality and morbidity in patients with T2D, and the manifestation of heart failure (HF) is common in these patients, negatively influencing life expectancy and quality of life [3]. The Framingham Heart Study reported that the risk of HF is twofold higher in men and threefold higher in women with T2D [4].

Data from the Pan American Health Organization (PAHO) and the World Health Organization (WHO) for 2014 indicate that the prevalence of diabetes in the Americas is $8.6 \%$ in men and $8.4 \%$ in women [5]. From this data set, the prevalence of macro- and microvascular complications in the Latin American T2D cohort was $13.8 \%$ and $15.2 \%$, respectively. Additionally, approximately half of the Latin American patients had hypertension (55.5\%) and hyperlipidemia (45.9\%) [6]. Despite a great deal of updated information being available, many patients fail to achieve their treatment goals. Furthermore, the IDF Atlas 2019 listed Brazil and Mexico among top ten countries with high healthcare expenditure due to diabetes in 2019 [1]. It is projected that, by 2025 the economic burden of diabetes care would be highest in Mexico (USD 8604 million) followed by Brazil (USD 7230 million), Argentina ( USD 1048 million), Colombia ( USD 828 million), and Venezuela (USD 742 million). Taking into account the increasing disease and economic burdens, it is important to prevent complications by achieving treatment goals which can result in cost-effective management of diabetes [7].

Primary care physicians (PCPs), who in most cases diagnose and manage patients with T2D, face multifactorial challenges that hinder translating the guidelines, which are often developed by specialists. Barriers to the effective management of T2D include limited resources, environmental constraints, limited knowledge and skills, lack of treatment adherence, or patient-related factors, such as social influences, perceptions and beliefs, education, lifestyle, among others [8-10]. Additionally, PCPs are often concerned about the medication issues, the complexity in developing personalized approach in the case of comorbidities, and cost of the medications [11]. The DEAL survey conducted among general practitioners from Latin American countries identified patient compliance issues in the T2D patients with regards to medication, glucose self-monitoring, diet, and exercise [12]. Additionally, Blasco et al. identified patient-specific barriers, such as paternalistic attitude, vertical communication, lack of patient-centric communication by healthcare professionals, and lack of support related to diet at home, in the Latin American region [13]. Education of PCPs and ensuring coordinated activity among different levels of health care is necessary for improved outcomes. The Municipality of Buenos Aires introduced an online diabetes care education program at the primary care level that reported significant improvement not only in the clinical outcomes at 1 year but also higher treatment adherence, better T2D control, and reduced cost of care [14]. Although multiple detailed guidelines provide guidance to specialists, very few guidelines have been developed to help the PCPs who treat patients with T2D $[15,16]$. 
This document provides consensus recommendations for PCPs to guide the diagnosis, assessment, and management of metabolic-cardio-renal risks in patients with T2D from the Latin America region. The primary objective of this consensus document is to integrate the metabolic, cardiac, and nephrological views in a single practical and simple guideline for the management of patients with T2D in Latin America, starting from the first contact with their PCP.

\section{METHODOLOGY}

The recommendations presented in this document are the result of a discussion among medical specialists (four endocrinologists, five cardiologists, and three nephrologists) and experts in clinical research. Existing scientific evidence on the prevention of complications in diabetes with a metabolic-cardio-renal approach was critically reviewed and discussed to formulate recommendations.

The level of evidence and the strength of the recommendation associated with each of them were not included in the development of the recommendations because of the complexity involved in exchanging the different scales used by the medical societies. Reference was made to the latest consensus guidelines from the European Society of Cardiology (ESC) and European Association for the Study of Diabetes (EASD), and American Association of Diabetes (ADA) for additional recommendations.

A questionnaire comprising 20 questions on different aspects of T2D management (including treatment inertia, early diagnosis and management of $\mathrm{CV}$ and renal diseases, and holistic perspective on T2D management) was sent to the respective experts prior to the meeting, which was held on 11 July 2019 at the University of Campinas, Sao Paulo State, Brazil. The consensus statements were drafted and reviewed by all the authors; sections of the manuscript were further refined through correspondence until a consensus was reached.

The recommendations are summarized in five steps:
1. Diagnosis.

2. Assessment of metabolic-cardio-renal risk.

3. Determination of target glycosylated hemoglobin (HbA1c), blood pressure (BP), and low-density lipoprotein cholesterol (LDL-C) levels.

4. Management of each risk factor.

5. Other general recommendations.

This article is based on previously conducted studies and does not contain any studies with human participants or animals performed by any of the authors.

\section{STEP 1: CONSENSUS RECOMMENDATIONS ON DIAGNOSIS OF DIABETES}

Diabetes occurs (particularly because of ethnicity) at a younger age (before 45 years) in the Latin American region, resulting in long-term exposure to hyperglycemia and, consequently, a greater risk of early complications [17]. Hence, the expert panel emphasizes a prompt evaluation and diagnosis of T2D. The consensus recommends similar diagnostic criteria (with some modification) as proposed by the ADA [18], as shown in Fig. 1. Diabetes can be diagnosed based on the fasting plasma glucose (FPG) value or on the 2-h PG value following oral consumption of $75 \mathrm{~g}$ glucose (oral glucose tolerance test), or on the HbA1c value. However, patients exhibiting classical symptoms of hyperglycemia can undergo a random plasma glucose test. Similar recommendations are provided by the Latin American consensus published in 2019 for T2D patients with hypertension [19].

\section{STEP 2: CONSENSUS RECOMMENDATIONS ON THE ASSESSMENT OF METABOLIC-CARDIO-RENAL RISKS}

The scientific evidence published between 2007 and 2017 report that, overall, $32.2 \%$ of patients with T2D developed CVD, attributing to $50 \%$ of 
Criteria for the diagnosis of T2D in adults (not pregnant)

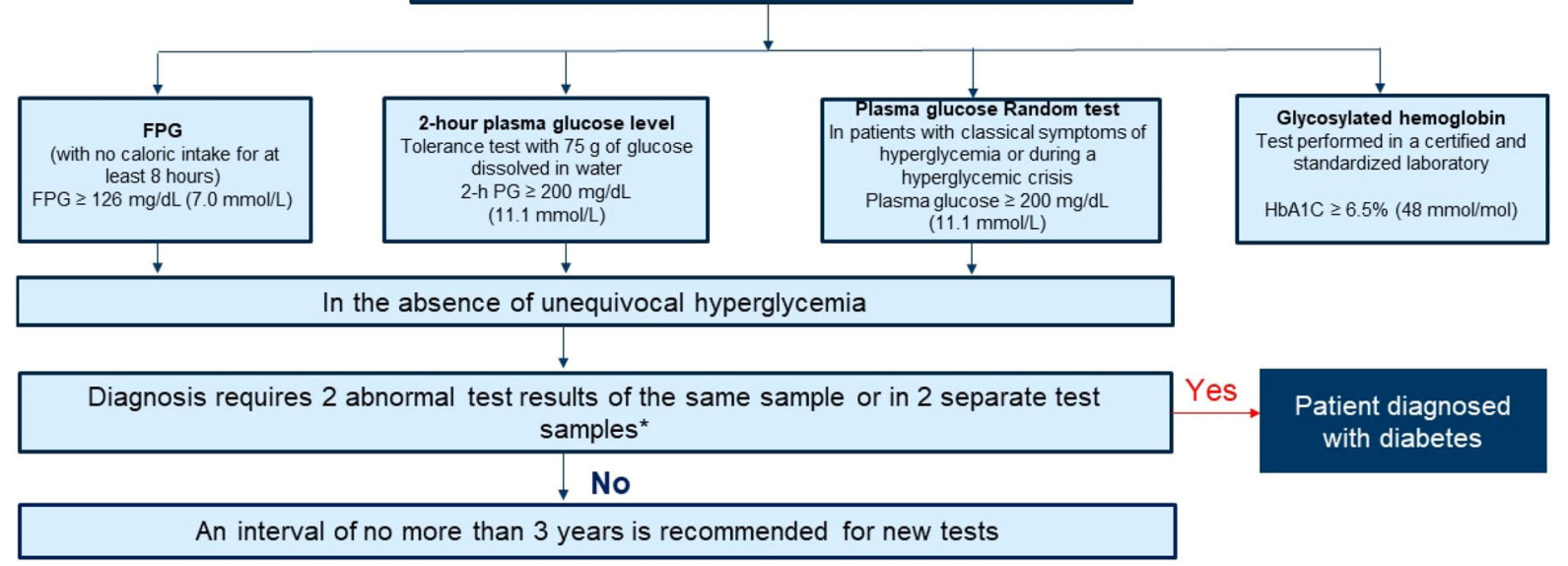

Fig. 1 Criteria for the diagnosis of type 2 diabetes in adults (not pregnant). Asterisk: The same tests can be used for screening and for diagnosis of patients with diabetes.
FPG Fasting plasma glucose, $H b A l c$ glycated hemoglobin, $P G$ plasma glucose, $T 2 D$ type 2 diabetes

studies included in the review, the 225 studies that used threshold to define GH (199 studies used a single threshold and 26 studies used several or continuous thresholds adjusted for patient age and/or sex) reported that the median GH was 135 (range 90.7-175) $\mathrm{mL} / \mathrm{min} / 1.73$ $\mathrm{m}^{2}$ [22]. As $\mathrm{GH}$ is considered to be a mechanism of damage and progression of kidney disease, it should be considered to be present in patients with decreased or normal kidney function [23].

Since the early 1980s, microalbuminuria has been considered to be a well-known marker of proteinuria, poor renal outcomes, and mortality in patients with T2D $[24,25]$. When the renal function is normal, microalbuminuria should be measured annually, whereas in the case of renal impairment or abnormalities, microalbuminuria should be assessed every 3 months [26]. In addition, the expert panel also recommends that it is possible to assess microalbuminuria on a monthly basis if there is a need to adjust treatment, until the objectives of the therapeutic change are reached. Recommendations from the ADA on the assessment of albuminuria and eGFR are in line with these recommendations [27]. The different recommended equations used for measuring eGFR are indicated in Box 1. 
Box 1 Recommended equations for measuring estimated glomerular filtration rate

1. Cockcroft-Gault (CG) equation:

$([140$ - age $] \times$ weight $[\mathrm{kg}]) /(\mathrm{sCr}[\mathrm{mg} / \mathrm{dL}] \times 72)$

$(\times 0.85$ for females $) \quad[74]$

2. Four-variable Modification of Diet in Renal Disease

(MDRD) equation traceable to IDMS reference:

$\left(175 \times[\mathrm{sCr}]^{-1.154} \times[\text { age }]^{-0.203}[\times 1.212\right.$ if black race $][\times 0.742$ if females] [75]

3. Chronic Kidney Disease Epidemiology Collaboration (CKD-EPI) equation:

$141 \times \min .(\mathrm{sCr} / \kappa, 1)^{\alpha} \times \max .(\mathrm{sCr} / \kappa$, $1)^{-1.209} \times 0.993^{\text {age }}[\times 1.018$ for females $][\times 1.159$ for black race $]^{\mathrm{a}}[76]$

The American Diabetes Association (ADA) guidelines recommend the MDRD formula while the present expert panel recommended using the CKD-EPI equation for measuring estimated glomerular filtration rate (eGFR)

IDMS Isotopic dilution mass spectrophotometry, $s \mathrm{Cr}$ serum creatinine

${ }^{\mathrm{a}} \kappa$ is 0.7 for females and 0.9 for males; $\alpha$ is -0.329 for females and -0.411 for males; $\mathrm{min}$. is $\mathrm{s} \mathrm{Cr}$ minimum value $/ \kappa$ or 1, max. is the $s \mathrm{Cr}$ maximum value $/ \kappa$ or 1

The risk parameters that a PCP should consider from the metabolic-cardio-renal perspective to identify T2D patients at a higher risk of developing associated morbidities are shown in Table 1 [26, 28]. This evaluation method is aimed at not only identifying the patient with T2D but also at identifying some of the elements of associated CVD risks. This stratification is used to define a patient's health status and allows a rapid assessment of metabolic-cardio-renal risk factors from the initial consultation. In the case of CVD and renal risk, the higher of the two values exhibited by the patient at the time of assessment is used. However, CVD risk and kidney disease are highly interrelated, and renal insufficiency is the most important CVD risk factor, even higher than tobacco use and dyslipidemia. Furthermore, albuminuria is, in addition to being an indicator of renal impact, a marker of endothelial damage [29]. In this context, we provide an example of a 75-year-old patient, weighing $94 \mathrm{~kg}$, undergoing evaluation.

The patient's BP is $145 / 85 \mathrm{mmHg}$, and test results are as follows: HbA1c, 6.9\%; creatinine, $1.5 \mathrm{mg} / \mathrm{dL}$; albuminuria, $185 \mathrm{mg} /$ day; lipid profile: total cholesterol, $205 \mathrm{mg} / \mathrm{dL}$; triglycerides, $165 \mathrm{mg} / \mathrm{dL}$; high-density lipoprotein cholesterol, $23 \mathrm{mg} / \mathrm{dL}$; and LDL-C, $149 \mathrm{mg} / \mathrm{dL}$. The GFR estimation by the Cockcroft-Gault equation is $56.6 \mathrm{~mL} / \mathrm{min} / 1.73 \mathrm{~m}^{2}$.

Based on the test results, the patient is diagnosed with diabetes, with a higher $\mathrm{CV}$ risk compared to renal or metabolic risk:

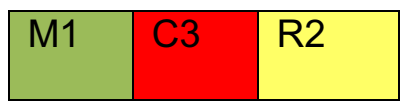

Stratifying patients based on their metabolic $(\mathrm{M})$, cardio $(\mathrm{C})$, and renal $(\mathrm{R})$ risk factors, as shown in color-coded image, will allow PCPs to identify patients who are at a greater risk and prioritize the treatment.

\section{STEP 3: CONSENSUS RECOMMENDATIONS ON ESTABLISHING HbA1c, BP, and LDL-C Goals}

The HbA1c, BP, and LDL-C goals may vary depending on the patient's history and are indicated in Table 2 as recommended by the ESC guidelines [30]. From the renal point of view, the objective is that every patient maintains glomerular filtration within normal limits (90-120 mL/min) without microalbuminuria. A Latin American consensus published in the same year recommends HbA1c of at least $6.5 \%$ and classifies hypertension into grade 1 (between $140 / 90$ and $159 / 99 \mathrm{mmHg}$ ), grade 2 (between $160 / 100$ and $179 / 109 \mathrm{mmHg}$ ), and grade $3(\geq 180 / 110 \mathrm{mmHg})$ [19]. Another Latin American consensus published in 2010 proposed treatment goals for $\mathrm{HbA} 1 \mathrm{c}$ as $<7 \%$, BP $\leq 130 / 80 \mathrm{mmHg}$, and LDL-C target as $<100 \mathrm{mg} / \mathrm{dL}$ [31].

The guideline published by the ESC in 2019 has amended lipid targets according to the CVD 
Table 1 Initial assessment of patients with type 2 diabetes

\begin{tabular}{|c|c|c|c|c|}
\hline \multirow[t]{2}{*}{ Area } & \multirow[t]{2}{*}{ Risk Parameter } & \multicolumn{3}{|c|}{ Treatment Objectives or Goals } \\
\hline & & 3 & 2 & 1 \\
\hline \multirow[t]{2}{*}{ Metabolic } & $\mathrm{HbA1c}$ & $>8 \%$ & $7 \%-8 \%$ & $<7 \%$ \\
\hline & Hypoglycemia & $\begin{array}{c}\text { Severe } \\
\text { hypoglycemia }\end{array}$ & Mild hypoglycemia & $\begin{array}{c}\text { Without } \\
\text { hypoglycemia }\end{array}$ \\
\hline \multirow[t]{2}{*}{ Cardiac } & $\mathrm{BP}(\mathrm{mm} \mathrm{Hg})$ & $>140 / 90$ & $>130 / 80$ and $<140 / 90$ & $\begin{array}{c}<130 / 80 \text { and } \\
>120 / 70\end{array}$ \\
\hline & LDL-C (mg/dL) & $>130$ & $>100$ and $<130$ & $<100$ \\
\hline \multirow[t]{2}{*}{ Renal } & GFR $\left(\mathrm{mL} / \mathrm{min} / 1.73 \mathrm{~m}^{2}\right)$ & $<30$ to $>150$ & $30-90$ & $90-150$ \\
\hline & Albuminuria & $\begin{array}{l}\text { Macroalbuminuria } \\
\qquad>300 \mathrm{mg} / \mathrm{g} \\
\text { (albumin/creatinine) }\end{array}$ & $\begin{array}{c}\text { Microalbuminuria } \\
\text { from } 30 \text { to } 300 \mathrm{mg} / \mathrm{g} \\
\text { (albumin/creatinine) }\end{array}$ & Absent or $<30 \mathrm{mg} / \mathrm{g}$ \\
\hline
\end{tabular}

$B P$ blood pressure, GFR glomerular filtration rate, $H b A 1 c$ glycosylated hemoglobin, $L D L-C$ low-density lipoprotein cholesterol

risk in patients with T2D. The ESC recommends an LDL-C target of $<100 \mathrm{mg} / \mathrm{dL}$ for patients with moderate $\mathrm{CV}$ risk, $<70 \mathrm{mg} / \mathrm{dL}$ for patients with high $\mathrm{CV}$ risk, and $<55 \mathrm{mg} / \mathrm{dL}$ for patients with very high $\mathrm{CV}$ risk [30].

\section{STEP 4: CONSENSUS RECOMMENDATIONS ON THE MANAGEMENT OF EACH RISK FACTOR}

\section{Metabolic Control}

\section{Glycosylated Hemoglobin}

Given the asymptomatic nature of diabetes, patients remain with high $\mathrm{HbA1c}$ values for years without treatment intensification, increasing the risk of microvascular complications. The DISCOVER study found that in Latin America, $80 \%$ of patients had an average HbA1c of $8.5 \%$ (vs. $7 \%$, suggested by the treatment guidelines). The study highlighted the clinical inertia in treatment intensification and the need for intensive risk factor screening to improve the prognosis of these patients from the Latin American region [6]. Additionally, it is mandatory to acknowledge strategies between physicians and patients to improve adherence and lifestyle changes. It is a process of communication and commitment.

Some recommendations to avoid clinical inertia are: 
Table 2 Glycosylated hemoglobin, blood pressure, and low-density lipoprotein cholesterol goals that may vary depending on special situations [30]

\begin{tabular}{|c|c|}
\hline $\begin{array}{l}\text { Risk } \\
\text { factor }\end{array}$ & Target \\
\hline $\mathrm{BP}$ & $\begin{array}{l}\text { SBP should be } 130 \mathrm{mmHg} \text { in patients with } \\
\text { DM; }<130 \mathrm{mmHg} \text { if tolerated, but } \\
\text { not }<120 \mathrm{mmHg} \\
\text { Older people ( }>65 \text { years): SBP goal is to } \\
\text { maintain between } 130 \text { and } 139 \mathrm{mmHg} \\
\text { DBP target is }<80 \mathrm{mmHg} \text { but } \\
\text { not }<70 \mathrm{mmHg}\end{array}$ \\
\hline HbAlc & $\begin{array}{l}\text { Younger patients with a short duration of DM } \\
\text { and no evidence of CVD should maintain } \\
\text { HbAlc } 6.0-6.5 \% \\
\text { Fragile, elderly patients with a long history of } \\
\text { DM, limited life expectancy, and multiple } \\
\text { comorbidities should maintain HbAlc }<8 \% \\
\text { or } \leq 9 \%\end{array}$ \\
\hline LDL-C & $\begin{array}{l}\text { DM patients with very high } \mathrm{CV} \\
\text { risk: }<55 \mathrm{mg} / \mathrm{dL} \\
\text { DM patients with high } \mathrm{CV} \text { risk: }<70 \mathrm{mg} / \mathrm{dL} \\
\text { DM patients with moderate } \mathrm{CV} \\
\text { risk: }<100 \mathrm{mg} / \mathrm{dL}\end{array}$ \\
\hline
\end{tabular}

$\mathrm{BP}$, blood pressure; CV, cardiovascular; CVD, cardiovascular disease; DBP, diastolic blood pressure; DM, diabetes mellitus; HbA1c, glycosylated hemoglobin; LDL-C, lowdensity lipoprotein cholesterol; SBP, systolic blood pressure

- Do not delay therapeutic escalation while awaiting adherence to lifestyle changes. Evidence-based clinical practice recommendations should be followed.

- Adapt a language that is appropriate to each patient.

- Agree on therapeutic goals with the patient; emphasize the importance of treatment adherence and the risk of poor metabolic control with the patient and seek his/her commitment.

- Discuss the asymptomatic nature of the disease and the need for periodic control with the patient.
- Discuss with the patient the progressive nature of the disease and the need to check blood sugar regularly despite being on treatment.

- Design a written follow-up agenda and set reminders.

The ESC guideline recommends structured self-monitoring of blood glucose (SMBG) and/or continuous glucose monitoring (CGM) to facilitate optimal glycemic control [30]. Continuous glucose monitoring (real-time or intermittent) helps overcome many limitations associated with the traditional HbA1c testing and SMBG by providing uniform tracks of the glucose concentration, thus reflecting intra- and interday glycemic excursions [32]. The international consensus recommends using CGM in conjunction with HbA1c in all patients with diabetes who are not achieving glycemic targets despite insulin therapy. Furthermore, it also emphasizes patient education and training for interpreting glucose data and improving treatment adherence [32].

\section{Therapeutic Management}

Recommendations for the Therapeutic Management of Blood Glucose Levels The expert panel recommends following a step-wise approach when the patient fails to achieve the HbA1c goal. The ADA/EASD guideline [33] and the ESC guideline [30] recommend sodiumglucose co-transporter 2 (SGLT2) inhibitors or glucagon-like peptide-1 (GLP-1) receptor agonists regardless of HbA1c level or individualized HbA1c target for patients with atherosclerotic CVD or high CVD risk. When HbA1c is $\geq 1.5 \%$ $(12.5 \mathrm{mmol} / \mathrm{mol})$ higher than the blood glucose target, many patients will require a combined dual therapy to achieve their HbA1c target level. In addition to pharmacological strategies, lifestyle changes and intensification of statin therapy are recommended to prevent $\mathrm{CV}$ complications [30]. However, if the patient is not at high CV risk, patient characteristics should be considered and relevant medication should be recommended.

The treatment decision algorithm (Fig. 2) is proposed as per the CVD risk categories defined by the ESC guidelines. The ESC guidelines 


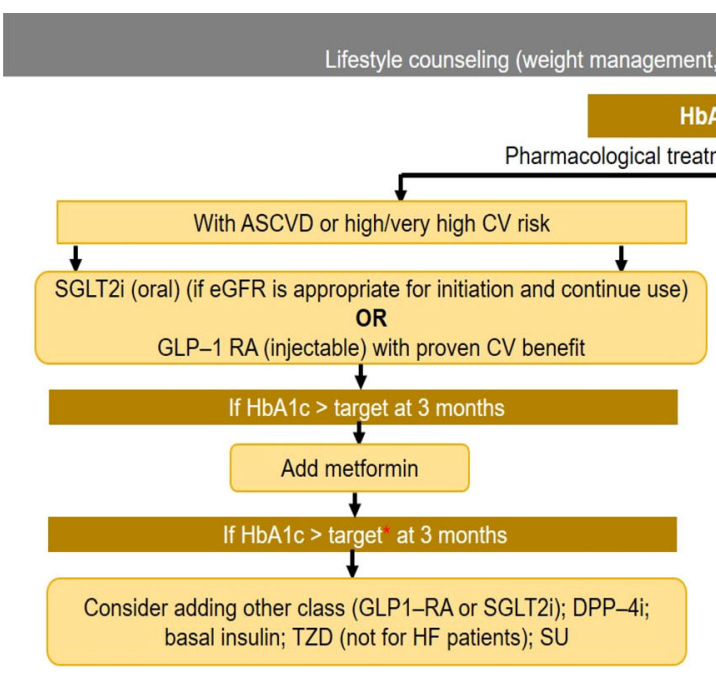

Fig. 2 Decision tree on recommendations for therapeutic management of blood glucose levels. Red asterisk: If HbAlc is $1.5 \%(12.5 \mathrm{mmol} / \mathrm{mol})$ higher than the blood glucose target, consider adding SGLT2 to metformin monotherapy. ASCVD, atherosclerotic cardiovascular disease; CV, cardiovascular; DPP-4i, dipeptidyl peptidase-4

Table 3 Cardiovascular risk categories in patients with diabetes [30]

\begin{tabular}{cl}
\hline $\begin{array}{l}\text { CV risk } \\
\text { level }\end{array}$ & Patient details \\
\hline $\begin{array}{c}\text { Very high } \\
\text { risk }\end{array}$ & $\begin{array}{c}\text { Patients with DM AND established CVD } \\
\text { OR with target organ damage }{ }^{a} \text { OR } \geq 3 \\
\text { major risk factors }\end{array}$ \\
High risk & $\begin{array}{c}\text { Patients without target organ damage and } \\
\text { any other additional risk factor but with }\end{array}$ \\
& $\begin{array}{c}\text { DM duration } \geq 10 \text { years } \\
\text { Moderate } \\
\text { risk }\end{array}$ \\
$\begin{array}{c}\text { Young patient with T2D (aged }<50 \text { years) } \\
\text { without any risk factors but with diabetes } \\
\text { duration of }<10 \text { years }\end{array}$ \\
\hline
\end{tabular}

CVD, cardiovascular disease; DM, diabetes mellitus; eGFR, estimated glomerular filtration rate; T1D, type 1 diabetes; T2D, type 2 diabetes

a Proteinuria, renal impairment defined as eGFR $>30 \mathrm{~mL} / \mathrm{min} / 1.73 \mathrm{~m}^{2}$, left ventricular hypertrophy, or retinopathy

' Age, hypertension, dyslipidemia, smoking, and obesity
2D patients

hysical activity, diet, guidance, and smoking cessation)

A1c target not met

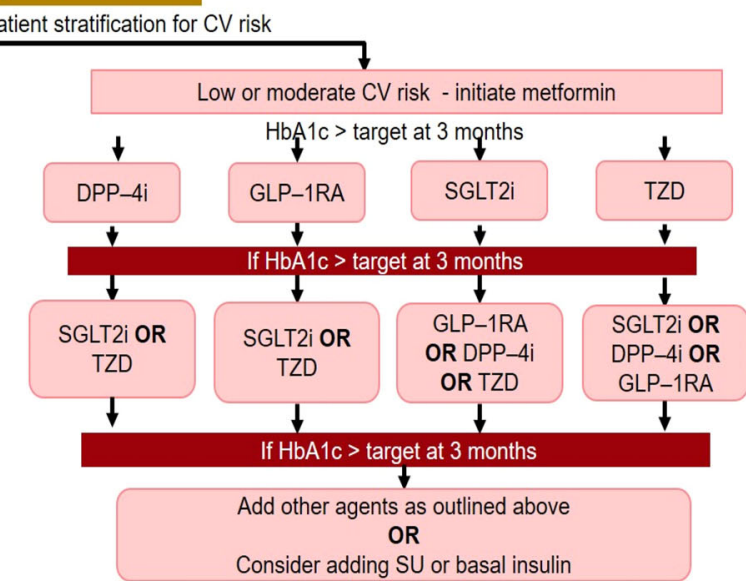

inhibitor; eGFR, estimated glomerular filtration rate; GLP1-RA, glucagon like peptide-1 receptor agonist; HbA1c, glycated hemoglobin; HF, heart failure; SGLT2i, sodium-glucose co-transporter 2 inhibitor; SU, sulfonylureas; T2D, type 2 diabetes; TZD, thiazolidinedione

stratify patients with T2D into very high risk, high risk, and moderate risk on the basis of the presence or absence of CVD, organ damage, risk factors (such as age, hypertension, dyslipidemia, smoking, and obesity), and the duration of diabetes (Table 3) [30].

The order for management recommendations is based on the following:

- When glycemic targets are not achieved with healthy lifestyle management alone, metformin should be preferred as the initial pharmacological therapy, unless contraindicated (when GFR $<45 \mathrm{~mL} / \mathrm{min} / 1.73 \mathrm{~m}^{2}$ ). Early intensive glucose control reduces progression of microvascular complications $[34,35]$. When the HbA1c target is not achieved within 3 months, dual therapy can be considered with other classes of medication, including sulfonylurea, dipeptidyl peptidase-4 (DPP-4) inhibitors, SGLT2 inhibitors, GLP-1 receptor agonist, or basal insulin.

- SGLT2 inhibitors (empagliflozin, canagliflozin, and dapagliflozin) offer high levels of 
Table 4 Timeline for follow-up of parameters

\begin{tabular}{llll}
\hline Parameter & $\begin{array}{l}\text { Initial } \\
\text { Visit }\end{array}$ & Follow-up & Yearly \\
\hline BP & Yes & Each visit & Yes \\
HbAlc & Yes & 3 months after drug change (otherwise, every 6 months) & Yes \\
Lipid profile (TC, LDL-C, HDL-C, & Yes & 3 months after drug change (otherwise, yearly) & Yes \\
$\quad$ TG) & Yes & Every 3 months in case of CRD or change in medication & Yes \\
Ionogram & Yes & Every 6 months or more frequently in case of renal & Yes \\
Microalbuminuria & & impairment & Yes \\
& Yes & Every 6 months or more frequently in case of renal & \\
Estimation of glomerular filtration & & impairment & \\
\hline
\end{tabular}

CRD, chronic renal disease; HbAlc, glycosylated hemoglobin; HDL-C, high-density lipoprotein cholesterol; LDL-C, lowdensity lipoprotein cholesterol; TC, total cholesterol; TG, triglycerides

CVD prevention and nephroprotection and hence can be considered as a primary recommendation in patients with high CVD risk [36-40]

- GLP-1 receptor agonists (liraglutide, semaglutide) offer CV benefits [41-43].

Concomitant use of GLP-1 receptor agonists and DPP-4 inhibitors is not recommended as this combination therapy provides marginal and nonsignificant glycemic control, offers minimal weight loss, and is not cost-effective [44, 45]. Thiazolidinediones (pioglitazone and rosiglitazone) are associated with a higher risk of incident HF (serious/severe) and should not be recommended in patients at risk of $\mathrm{HF}$ or with history of HF [46-48]. SGLT2 inhibitors and metformin should be the first-choice drugs (Tables 4, 5).

\section{Consultation with Specialists in Diabetes is indicated in the Following Cases}

- In case of hyperglycemia that is difficult to manage with drugs (patients with HbA1c above target even after combination therapy including two to three oral antidiabetic drugs), patients with atherosclerotic CVD, or patients at the beginning of complex (basal-bolus) insulin regimen.
- In case of microvascular complications, such as diabetic neuropathy, retinopathy, and nephropathy.

- In the presence of hypoglycemia episodes despite adjustments in treatment where hypoglycemia is defined as glucose levels $<70 \mathrm{mg} / \mathrm{dL} \quad$ (symptomatic or asymptomatic).

\section{Cardiac Control}

\section{Recommendations for the Therapeutic Management of $B P$ \\ Pharmacological Treatment}

- Evidence suggests that treatment should be started with an angiotensin-converting enzyme inhibitor (ACEI); patients who are intolerant to ACEI should receive an angiotensin receptor blocker (ARB). ACEIs or ARBs have beneficial effects on $\mathrm{CV}$ and non-CV mortality in patients with high CV risk [49].

- BP control frequently requires a combined pharmacological treatment with a renin-angiotensin system (RAS) blocker and a calcium blocker or a thiazide-type diuretic, particularly in the presence of proteinuria and microalbuminuria [50-52].

- A combination of two classes of drugs (RAS or ACEIs or ARBs combined with a calcium channel blocker or thiazide), preferably 
Table 5 Summary of consensus recommendations

\section{Summary of consensus recommendations}

Step 1: Criteria for confirming diagnosis

FPG $\geq 126 \mathrm{mg} / \mathrm{dL}(7.0 \mathrm{mmol} / \mathrm{L})$

$2 \mathrm{hPG} \geq 200 \mathrm{mg} / \mathrm{dL}(11.1 \mathrm{mmol} / \mathrm{L})$

$\mathrm{HbAlc} \geq 6.5 \%(48 \mathrm{mmol} / \mathrm{mol})$

$\mathrm{RPG} \geq 200 \mathrm{mg} / \mathrm{dL}(11.1 \mathrm{mmol} / \mathrm{L})$

Step 2: Assessment of metabolic-cardio-renal risk

At the first visit, it is recommended to evaluate the metabolic-cardio-renal baseline status through measurement of HbAlc, LDL-C, BP, microalbuminuria, eGFR and renal hyperfiltration

Patients should be further stratified into very high risk, high risk, and moderate risk on the basis of the presence or absence of CVD, organ damage, risk factors (such as age, hypertension, dyslipidemia, smoking, and obesity), and the duration of diabetes

Step 3: Establish HbAlc, BP and LDL-C goals

HbAlc, BP, and LDL-C goals may vary depending on the patient's history (duration of diabetes, CVD, other CV risk factors, renal status, and other comorbidities)

Step 4: Management of each risk factor

Metabolic control

Improved prognosis of patients from the diagnosis is needed to overcome clinical inertia

Patients with ASCVD or high CV risk should receive SGLT2 inhibitor (oral) or GLP1 agonist (injectable) before initiating metformin therapy [30]

Patient characteristics should be considered and relevant medications (starting with metformin, followed by DPP-4i, GLP-1 agonist, SGLT2 inhibitor, and TZD) should be recommended for patients with low or moderate CV risk

When $\mathrm{HbAlc}$ is $\geq 1.5 \%(12.5 \mathrm{mmol} / \mathrm{mol})$ over the blood glucose target, patients should receive a dual therapy including metformin

Consult a diabetes specialist when hyperglycemia is difficult to manage with drugs, or at the beginning of a complex insulin regimen, microvascular complications such as diabetic neuropathy, retinopathy and nephropathy, and incidence of hypoglycemia episodes (glucose levels $<70 \mathrm{mg} / \mathrm{dL}$ ) despite adjustments in treatment

CVD control

It is recommended to start treatment with ACEI; however, ARB can be recommended to patients intolerant to ACEIs [49]

Statins are recommended as the first line at the doses required to achieve LDL-C goals [53]

If LDL-C target is not achieved with statins at maximum doses, ezetimibe should be indicated

Consult cardiologist if the patient has a history of CVD or multiple risk factors, suspicion or history of HF, CAD, or hypertension 
Table 5 continued

Summary of consensus recommendations

Nephrological control

Prescribe a SGLT2 inhibitor to reduce renal hyperfiltration and protect the kidneys [55-57]

Consult a nephrologist when GFR $<60 \mathrm{~mL} / \mathrm{min}$, accelerated decrease (> 15\%) in GFR within 12 months, or increase

in serum creatinine ( $>20 \%$ from baseline) or albumin $(>30 \mathrm{mg} / \mathrm{dL}$ ) occurs

Step 5: General recommendations

Low- to moderate-carbohydrate diets have a greater effect on achieving glycemic control compared with high-

carbohydrate diets [61]

The Mediterranean diet supplemented with olive oil and/or nuts reduces the incidence of CV events [60]

Moderate to vigorous physical activity of $\geq 150 \mathrm{~min} /$ week is recommended [30]

Advise all patients not to use cigarettes or other tobacco products or electronic cigarettes because of health risks

Aspirin use is not recommended as primary prevention, but it may be considered in patients with high CV risk in the absence of contraindication. Other antiplatelet drugs such as clopidogrel is recommended in aspirin intolerant patients or in combination with low-dose aspirin as dual antiplatelet therapy [30]

2hPG, 2-hour plasma glucose; ACEI, angiotensin-converting enzyme inhibitor; ADA, American Diabetes Association; $\mathrm{ARB}$, angiotensin receptor blocker; $\mathrm{ASCVD}$, atherosclerotic cardiovascular disease; $\mathrm{BP}$, blood pressure; $\mathrm{CAD}$, coronary artery disease; CV, cardiovascular; CVD, cardiovascular disease; LDL-C, low-density lipoprotein cholesterol; DPP-4i, dipeptidyl peptidase-4 inhibitor; eGFR, estimated glomerular filtration rate; FPG, fasting plasma glucose; GFR, glomerular filtration rate; GLP1-RA, glucagon-like peptide-1 receptor agonist; HbAlc, glycated hemoglobin; HF, heart failure; LDL-C, low density lipoprotein cholestrol; RPG, random plasma glucose; SGLT2i, sodium-glucose co-transporter 2 inhibitor; SU, sulfonylureas; T2D, type 2 diabetes; TZD, thiazolidinedione

combined in a single pill for improved adherence, can be recommended as the first-line treatment $[19,52]$. In case the dual treatment fails, a triple combination (RAS and calcium channel blocker combined with diuretic) can be considered. However, combined therapy with an ACEI and ARB must be avoided $[19,52]$.

\section{Controlling LDL-C}

- Statins are recommended as the first-line treatment at the doses required to achieve LDL-C goals [53].

- If the LDL-C target is not achieved with statins at maximum doses, ezetimibe should be added to the treatment regimen.

- In patients with high CV risk (multiple risk factors or CV history) who do not achieve target levels with a statin and ezetimibe or with intolerance to statins, a consultation with a cardiologist or endocrinologist is indicated to consider the need of protein convertase subtilisin-kexin 9 (PCSK9) inhibitors.

\section{Consult a Cardiologist in the Following Circumstances}

- The patient has a history of CVD or multiple risk factors.

- If there is a suspicion or history of HF (patients presenting with dyspnea, orthopnea, fatigue, edema in extremities, irregular heartbeat, and reduced ability to exercise).

- If there is a suspicion of coronary artery disease (patients presenting with pain and/or discomfort, tightness, burning sensation in chest, arms, shoulders, etc., dyspnea).

- Difficult to manage patients whose hypertension is not controlled even on three different classes of hypertensives including 
diuretics (office BP is $>130 / 90 \mathrm{mmHg}$ ) and dyslipidemia (LDL-C of $>100 \mathrm{mg} / \mathrm{dL}$ ) despite on maximum tolerated dose of statins and ezetimibe.

\section{Renal Control}

Renal hyperfiltration and microalbuminuria should be included as treatment goals in patients with diabetes [23-25]. As both of these are prognostic markers of renal and CV risk, the expert panel recommended monitoring a pathophysiological mechanism of renal damage.

Initial GH is triggered by excess glucose at the proximal glomerular tubules, with a consequent increase in proximal reabsorption of glucose and sodium, which results in the activation of the tubuloglomerular feedback system. This leads to a reduction in sodium reaching the distal segments. The macula densa detects a decrease in distal sodium concentration, leading to the vasodilation of afferent arterioles and, consequently, an increase in intraglomerular pressure. Blocking glucose and sodium reabsorption in the proximal tubules corrects this situation and improves renal and $\mathrm{CV}$ prognosis from the early stages of the disease [54].

\section{Pharmacological Treatment}

- SGLT2 inhibitors have been shown to significantly reduce eGFR decline, risk of microalbuminuria, macroalbuminuria, endstage renal disease, and nephropathy compared to controls. Furthermore, SGLT2 inhibitors reduced serum creatinine doubling, and renal death in patients with eGFR $>60$ and $<60 \mathrm{~mL} / \mathrm{min} / 1.73 \mathrm{~m}^{2}[55,56]$. These outcomes were supported by the recently published DAPA-CKD trial that reported a significantly lower risk of a sustained decline in the eGFR of at least $50 \%$, end-stage kidney disease, or death from renal causes after dapagliflozin treatment compared to placebo in patients with CKD regardless of the presence or absence of diabetes [57]. An SGLT2 inhibitor should be prescribed to reduce renal hyperfiltration and to protect the kidneys in patients with T2D.

- Prescribe an ACEI or ARB, but not as combined therapy at the same time, in case of microalbuminuria or hypertension [52].

- Monitor potassium and creatinine levels and GFR if ACEI, ARB, or diuretics are used

- Avoid nephrotoxic drugs, such as non-steroid anti-inflammatory drugs, aminoglycosides, and iodinated contrast media.

\section{Consult a Nephrologist in the Following}

Circumstances

- If GFR $<60 \mathrm{~mL} / \mathrm{min} / 1.73 \mathrm{~m}^{2}$.

- When an accelerated decrease in GFR occurs ( $>15 \%$ in 12 months).

- In case of increase in serum creatinine ( $>20 \%$ from baseline).

- In case of persistent albuminuria despite treatment $(>30 \mathrm{mg} / \mathrm{dL})$.

\section{STEP 5: OTHER GENERAL RECOMMENDATIONS}

\section{Diet and Physical Activity}

As patients with diabetes are often overweight, changing dietary intake to bring about a reduction in energy consumption is a key component in the treatment of diabetes. A number of patient-specific factors, such as patient adherence, beliefs, and knowledge of diabetes and how it affects self-management 
$[58,59]$. In this regard, PCPs need to identify patient-specific barriers and provide counseling to influence patient perception of diabetes and compliance to self-management. The physician's expertise is essential in the development, implementation, and evaluation of any intervention designed to reduce and/or control overweight, obesity, and other comorbidities.

The Mediterranean diet supplemented with olive oil and/or nuts reduces the incidence of $\mathrm{CV}$ events in patients at high CV risk [60]. In addition to glucose-lowering therapy, low- to moderate-carbohydrate diets have been shown to have a greater effect on achieving glycemic control compared with high-carbohydrate diets [61].

Moderate to vigorous physical activity substantially reduces $\mathrm{CV}$ and overall mortality risks in patients with type 1 diabetes and T2D [62-64]. ESC/EASD guidelines recommend $\geq 150 \mathrm{~min} /$ week of moderate to vigorous physical activity [30]. A Latin American consensus guideline recommends consuming a balanced isocaloric diet comprising all nutrients (with 50-55\% energy from carbohydrates, $20-25 \%$ from protein, and $20-30 \%$ from fats, maintaining a ratio of 1:1:1 among saturated, unsaturated, and polyunsaturated fats) [19].

\section{Tobacco Withdrawal: Tobacco and Electronic Cigarettes}

Smoking, passive or active, significantly increases the risk of diabetes, CVD, and premature death [65-68]. Advise all patients not to smoke cigarettes, other tobacco products, or electronic cigarettes. Although motivational interviewing, smoking cessation counseling, and other forms of treatment are considered to be a routine component of diabetes care, evidence is lacking on the efficacy and safety of these interventions [69-73].

\section{Antiplatelet Drugs}

Clinical judgment should be used regarding antiplatelet drugs because of the risks of bleeding. Aspirin use is not recommended for primary prevention, but may be considered in patients with high $\mathrm{CV}$ risk in the absence of contraindications. Alternatively, the ESC guideline recommends clopidogrel in aspirinintolerant patients or in combination with lowdose aspirin as dual antiplatelet therapy (DAPT). Furthermore, patients with diabetes and acute coronary syndrome and those who undergo percutaneous coronary intervention or coronary artery bypass graft can receive ticagrelor or prasugrel with aspirin for 1 year [30].

\section{LIMITATIONS}

This consensus guideline has some limitations. As the main objective of this consensus document was to provide a pragmatic guide to busy PCPs on the diagnosis, assessment, and management of metabolic-cardio-renal risks in patients with $\mathrm{T} 2 \mathrm{D}$, it does not provide the level of evidence or the grade of the recommendation, and it does not discuss published evidence in detail. These recommendations are based on expert opinion. Secondly, specific recommendations focusing on special patient populations, such as elderly and frail patients, patients with type 1 diabetes, patients with a history of HF, CKD, and obesity, are not discussed in detail. Thirdly, the consensus document does not include other micro- and macrovascular complications.

\section{RECOMMENDATIONS AND ACTIONS}

Although patients and PCPs are at the core of diabetes management, multilevel efforts at the community, regional, and national level will help increase the awareness, early diagnosis and detection of associated comorbidities, resulting in the effective management of T2D (Box 2). 
Box 2 Recommendations and actions

\section{At the national level:}

Frequent updates of treatment guidelines

Facilitate access to drug treatment

Include SGLT2 inhibitors in the guidelines for the prevention and treatment of diabetic nephropathy and CV mortality

Recommend GLP-1 receptor agonists to reduce CV events

Change the paradigm of only looking for albuminuria in the face of evidence of increased chronic kidney disease without proteinuria

Improve access to treatments with statins or antihypertensive agents (depending on the case) that prevent $\mathrm{CV}$ events

Recognition in the guidelines that glycemic control is an essential part of treatment, but now that we have medications that impact CV outcomes, we must prioritize this evaluation and treatment because not all antidiabetic drugs will have the same impact on CVD

\section{At the regional level:}

Facilitate access to specialized healthcare

Facilitate access to HbAlc measurement

Medical education to key decision-makers

Facilitate access to biomarkers for the diagnosis of $\mathrm{HF}$

Develop high-level risk factor care centers for referral

\section{At the local level:}

Regular interdisciplinary meetings with discussion of clinical cases

Education by physicians to patients and families; involving family members in achieving goals

Audits to evaluate processes and allow the expression of the impact of different measures

Internal protocols and self-assessments on goals and protocol adherence and incentives for the achievement of therapeutic goals

Electronic medical record with alerts when HbAlc is out of range and confirm with the physician if the same treatment continues

Report the results of studies with SGLT2 inhibitors with benefit in renal events and CV disease (especially HF and CV death)

Improve awareness of HF risk in diabetes and how to screen for it

Education on medications with $\mathrm{CV}$ impact

Continuing medical education on how to translate clinical studies into practice and management of risk factors

Engagement of the PCP in the management of patients with high metabolic-cardio-renal risk and referral to specialists

$C V$ cardiovascular, $C V D$ cardiovascular disease, GLP-1 glucagon like peptide-1, HbAlc glycated hemoglobin, $H F$ heart failure, $P C P$ primary care physician, $S G L T 2$ sodium-glucose transport protein 2 


\section{CONCLUSION}

Primary care physicians are the first point of contact for patients with T2D and can play a unique role in providing a patient-centric approach in T2D management. Although multiple treatment options for T2D are available, in most cases, detailed guidelines have been developed for specialists. Very few guidelines are drawn up with the intention to provide PCPs with practical approaches to treat patients with T2D.

This statement aims to provide a practical comprehensive approach for PCPs to address multifactorial (metabolic-cardio-renal) assessment of patients with diabetes. As diabetes is progressive in nature, not only glycemic control but also the prevention of CV events and renal injury is important to reduce morbidity and mortality. In this regard, identifying and managing specific risk factors and treating them with an equal priority is important.

The existing clinical evidence suggests that SGLT2 inhibitors and GLP-1 receptor agonists not only provide effective glycemic control but also independently improve $\mathrm{CV}$ outcome. Additionally, PCPs can recommend SGLT2 inhibitor for nephroprotection in patients with T2D. PCPs also need to emphasize the importance of lifestyle modification and include counseling on diet, physical activity, and tobacco cessation in their management regimen. Additionally, multilevel efforts at the community, regional, and national level are necessary for the effective management of T2D.

\section{ACKNOWLEDGEMENTS}

Springer Healthcare is not responsible for the validity of guidelines it publishes.

Funding. Funding for this study and the Rapid Service Fee were provided by AstraZeneca. The views expressed in this paper are those of the authors and not necessarily those of the funders.
Medical Writing Assistance. The authors would like to acknowledge Ashwini Atre and Ramu Periyasamy (Indegene Pvt. Ltd., Bangalore, India) for literature review and medical writing support in developing the manuscript. Support for this assistance was funded by AstraZeneca.

Authorship. All named authors meet the International Committee of Medical Journal Editors (ICMJE) criteria for authorship for this article, take responsibility for the integrity of the work as a whole, and have given their approval for this version to be published.

Disclosures. Roopa Mehta reports personal fees from AstraZeneca, Novo Nordisk, Eli Lilly, Sanofi, Boehringer Ingelheim, and Abbot outside the submitted work. Mariano Giorgi reports personal fees from Novo Nordisk, Sanofi, and Raffo outside the submitted work. Rodolfo Lahsen reports personal fees and non-financial support from Eli Lilly, Sanofi, AstraZeneca, Boehringer Ingelheim, Merck, Novartis, and Novo Nordisk; personal fees from Merck, Sharp \& Dohme, Axon Pharma, Laboratorio ChileTeva, Tecnofarma during the conduct of the study outside the submitted work. Pablo Raffaele, Chih Hao Chen-Ku, Daniel Pichel, Francisco Padilla, Javier Arango Álvarez, José Esteban Costa Gil, Juan Esteban Gómez Mesa, Andrei C. Sposito and Antonio Mendez Duran have nothing to disclose.

Compliance with Ethics Guidelines. This article is based on previously conducted studies and does not contain any studies with human participants or animals performed by any of the authors.

Open Access. This article is licensed under a Creative Commons Attribution-NonCommercial 4.0 International License, which permits any non-commercial use, sharing, adaptation, distribution and reproduction in any medium or format, as long as you give appropriate credit to the original author(s) and the source, provide a link to the Creative Commons licence, and indicate if changes were made. The images or other third party material 
in this article are included in the article's Creative Commons licence, unless indicated otherwise in a credit line to the material. If material is not included in the article's Creative Commons licence and your intended use is not permitted by statutory regulation or exceeds the permitted use, you will need to obtain permission directly from the copyright holder. To view a copy of this licence, visit http:// creativecommons.org/licenses/by-nc/4.0/.

\section{REFERENCES}

1. International Diabetes Federation. IDF diabetes atlas, 9th edition 2019. Brussels: International Diabetes Federation; 2019.

2. Chatterjee S, Khunti K, Davies MJ. Type 2 diabetes. Lancet. 2017;389(10085):2239-51.

3. Verma S, Jüni P, Mazer CD. Pump, pipes, and filter: do SGLT2 inhibitors cover it all? Lancet. 2019;393(10166):3-5.

4. Kannel WB. Diabetes and cardiovascular disease. The Framingham study. JAMA. 1979;241(19): 2035-8.

5. Pan American Health Organization/World Health Organization. Health situation in the Americas: core indicators 2017. 2017. https://www.iris.paho. org/handle/10665.2/34329. Accessed 4 May.

6. Chen-Ku CH, Gonzalez-Galvez G, Vásquez M, et al. Vascular complications in patients with type 2 diabetes: prevalence and comorbidities in 6 countries of Latin America (a cohort of the discover study program). Endocr Pract. 2019;25(10): 994-1002.

7. Arredondo A. Universal coverage and economic burden from epidemiological changes of diabetes in Latin America. J Glob Health. 2016;6(2): 020309.

8. Santos Cavaiola T, Kiriakov Y, Reid T. Primary care management of patients with type 2 diabetes: overcoming inertia and advancing therapy with the use of injectables. Clin Ther. 2019;41(2):352-67.

9. Rushforth B, McCrorie C, Glidewell L, Midgley E, Foy R. Barriers to effective management of type 2 diabetes in primary care: qualitative systematic review. Br J Gen Pract. 2016;66(643):e114-27.

10. Gavin JR, Freeman JS, Shubrook JH, Lavernia F. Type 2 diabetes mellitus: practical approaches for primary care physicians. J Am Osteopath Assoc. 2011;111:S3-12.

11. van Bruggen $\mathrm{R}$, Gorter $\mathrm{K}$, Stolk RP, Zuithoff $\mathrm{P}$, Klungel OH, Rutten GEHM. Refill adherence and polypharmacy among patients with type 2 diabetes in general practice. Pharmacoepidemiol Drug Saf. 2009;18(11):983-91.

12. Lopez Stewart G, Tambascia M, Rosas Guzmán J, Etchegoyen F, Ortega Carrión J, Artemenko S. Control of type 2 diabetes mellitus among general practitioners in private practice in nine countries of Latin America. Rev Panam Salud Pública. 2007;22(1):12-20.

13. Blasco-Blasco M, Puig-García M, Piay N, Lumbreras B, Hernández-Aguado I, Parker LA. Barriers and facilitators to successful management of type 2 diabetes mellitus in Latin America and the Caribbean: a systematic review. PLoS ONE. 2020;15(9): e0237542.

14. Prestes M, Gayarre MA, Elgart JF, et al. Improving diabetes care at primary care level with a multistrategic approach: results of the DIAPREM programme. Acta Diabetol. 2017;54(9):853-61.

15. Seidu S, Cos X, Brunton S, Harris SB, Jansson SPO, Mata-Cases $M$, et al. A disease state approach to the pharmacological management of type 2 diabetes in primary care: a position statement by primary care diabetes Europe. Prim Care Diabetes. 2020. https:// doi.org/10.1016/j.pcd.2020.05.004.

16. Hambling CE, Khunti $\mathrm{K}$, Cos $\mathrm{X}$, et al. Factors influencing safe glucose-lowering in older adults with type 2 diabetes: A PeRsOn-centred ApproaCh To IndiVidualisEd (PROACTIVE) glycemic goals for older people. Prim Care Diabetes. 2019;13(4): 330-52.

17. Jiménez-Corona A, Rojas R, Gómez-Pérez FJ, Aguilar-Salinas CA. Early-onset type 2 diabetes in a Mexican survey: results from the National Health and Nutrition Survey 2006. Salud Publica Mex. 2010;52:S27-35.

18. American Diabetes Association. 2. Classification and diagnosis of diabetes: standards of medical care in diabetes-2019. Diabetes Care. 2019;42 (Suppl 1):S13-S28.

19. López-Jaramillo P, Barbosa E, Molina DI, et al. Latin American Consensus on the management of hypertension in the patient with diabetes and the metabolic syndrome. J Hypertens. 2019;37(6): 1126-47.

20. Einarson TR, Acs A, Ludwig C, Panton UH. Prevalence of cardiovascular disease in type 2 diabetes: a systematic literature review of scientific evidence 
from across the world in 2007-2017. Cardiovasc Diabetol. 2018;17(1):83.

21. Koye DN, Magliano DJ, Nelson RG, Pavkov ME. The global epidemiology of diabetes and kidney disease. Adv Chronic Kidney Dis. 2018;25(2):121-32.

22. Cachat F, Combescure C, Cauderay M, Girardin E, Chehade H. A systematic review of glomerular hyperfiltration assessment and definition in the medical literature. Clin J Am Soc Nephrol. 2015;10(3):382-9.

23. Jerums G, Premaratne E, Panagiotopoulos S, MacIsaac RJ. The clinical significance of hyperfiltration in diabetes. Diabetologia. 2010;53(10):2093-104.

24. Viberti GC, Jarrett RJ, Mahmud U, Hill RD, Argyropoulos A, Keen H. Microalbuminuria as a predictor of clinical nephropathy in insulin-dependent diabetes mellitus. Lancet. 1982;319(8287):1430-2.

25. Mogensen CE. Microalbuminuria predicts clinical proteinuria and early mortality in maturity-onset diabetes. N Engl J Med. 1984;310(6):356-60.

26. Vassalotti JA, Centor R, Turner BJ, Greer RC, Choi $\mathrm{M}$, Sequist TD. Practical approach to detection and management of chronic kidney disease for the primary care clinician. Am J Med. 2016;129(2):153162.e7.

27. American Diabetes Association. 11. Microvascular Complications and Foot Care: Standards of Medical Care in Diabetes-2020. Diabetes Care. 2020 Jan 1;43(Supplement 1):S135-51.

28. Stolar M. Addressing cardiovascular risk in patients with type 2 diabetes: focus on primary care. Am J Med Sci. 2011;341(2):132-40.

29. Seliger SL, Salimi S, Pierre V, Giffuni J, Katzel L, Parsa A. Microvascular endothelial dysfunction is associated with albuminuria and CKD in older adults. BMC Nephrol. 2016;17(1):82.

30. Cosentino F, Grant PJ, Aboyans V, et al. 2019 ESC guidelines on diabetes, pre-diabetes, and cardiovascular diseases developed in collaboration with the EASD. Eur Heart J. 2020;41(2):255-323.

31. Guzmán JR, Lyra R, Aguilar-Salinas CA, et al. Treatment of type 2 diabetes in Latin America: a consensus statement by the medical associations of 17 Latin American countries. Rev Panam Salud Pública. 2010;28(6):463-71.

32. Danne $\mathrm{T}$, Nimri R, Battelino $\mathrm{T}$, et al. International consensus on use of continuous glucose monitoring. Diabetes Care. 2017;40(12):1631-40.
33. Buse JB, Wexler DJ, Tsapas A, et al. 2019 update to: Management of hyperglycemia in type 2 diabetes, 2018. A consensus report by the American Diabetes Association (ADA) and the European Association for the Study of Diabetes (EASD). Diabetes Care. 2020;43(2):487-93.

34. Turner R. Effect of intensive blood-glucose control with metformin on complications in overweight patients with type 2 diabetes (UKPDS 34). Lancet. 1998;352(9131):854-65.

35. Holman RR, Paul SK, Bethel MA, Matthews DR, Neil HAW. 10-Year follow-up of intensive glucose control in type 2 diabetes. N Engl J Med. 2008;359(15): 1577-89.

36. Zinman B, Wanner C, Lachin JM, et al. Empagliflozin, cardiovascular outcomes, and mortality in type 2 diabetes. N Engl J Med. 2015;373(22): 2117-28.

37. Wiviott SD, Raz I, Bonaca MP, et al. Dapagliflozin and cardiovascular outcomes in type 2 diabetes. N Engl J Med. 2019;380(4):347-57.

38. Zelniker TA, Wiviott SD, Raz I, et al. Comparison of the effects of glucagon-like peptide receptor agonists and sodium-glucose cotransporter 2 inhibitors for prevention of major adverse cardiovascular and renal outcomes in type 2 diabetes mellitus. Circulation. 2019;139(17):2022-31.

39. Vallon V, Thomson SC. Targeting renal glucose reabsorption to treat hyperglycaemia: the pleiotropic effects of SGLT2 inhibition. Diabetologia. 2017;60(2):215-25.

40. Wanner C, Inzucchi SE, Lachin JM, et al. Empagliflozin and progression of kidney disease in type 2 diabetes. N Engl J Med. 2016;375(4):323-34.

41. Zelniker TA, Wiviott SD, Raz I, et al. SGLT2 inhibitors for primary and secondary prevention of cardiovascular and renal outcomes in type 2 diabetes: a systematic review and meta-analysis of cardiovascular outcome trials. Lancet. 2019;393(10166):31-9.

42. Marso SP, Daniels GH, Brown-Frandsen K, et al. Liraglutide and cardiovascular outcomes in type 2 diabetes. N Engl J Med. 2016;375(4):311-22.

43. Marso SP, Bain SC, Consoli A, et al. Semaglutide and cardiovascular outcomes in patients with type 2 diabetes. N Engl J Med. 2016;375(19):1834-44.

44. Nauck MA, Kahle M, Baranov O, Deacon CF, Holst JJ. Addition of a dipeptidyl peptidase- 4 inhibitor, sitagliptin, to ongoing therapy with the glucagonlike peptide-1 receptor agonist liraglutide: a 
randomized controlled trial in patients with type 2 diabetes. Diabetes Obes Metab. 2017;19(2):200-7.

45. Lajthia E, Bucheit JD, Nadpara PA, et al. Combination therapy with once-weekly glucagon like peptide- 1 receptor agonists and dipeptidyl peptidase- 4 inhibitors in type 2 diabetes: a case series. Pharm Pract (Granada). 2019;17(4):1588.

46. Dormandy JA, Charbonnel B, Eckland DJ, et al. Secondary prevention of macrovascular events in patients with type 2 diabetes in the PROactive Study (PROspective pioglitAzone Clinical Trial In macroVascular Events): a randomised controlled trial. Lancet. 2005;366(9493):1279-89.

47. DREAM (Diabetes REduction Assessment with ramipril and rosiglitazone Medication) Trial Investigators. Effect of rosiglitazone on the frequency of diabetes in patients with impaired glucose tolerance or impaired fasting glucose: a randomised controlled trial. Lancet. 2006;368(9541):1096-105.

48. Hernandez AV, Usmani A, Rajamanickam A, Moheet A. Thiazolidinediones and risk of heart failure in patients with or at high risk of type 2 diabetes mellitus. Am J Cardiovasc Drugs. 2011;11(2):115-28.

49. Tocci G, Paneni F, Palano F, et al. Angiotensinconverting enzyme inhibitors, angiotensin II receptor blockers and diabetes: a meta-analysis of placebo-controlled clinical trials. Am J Hypertens. 2011;24(5):582-90.

50. Lindholm LH, Ibsen H, Dahlöf B, et al. Cardiovascular morbidity and mortality in patients with diabetes in the Losartan Intervention For Endpoint reduction in hypertension study (LIFE): a randomised trial against atenolol. Lancet. 2002;359(9311):1004-10.

51. Niskanen L, Hedner T, Hansson L, Lanke J, Niklason A. Reduced cardiovascular morbidity and mortality in hypertensive diabetic patients on first-line therapy with an ACE inhibitor compared with a diuretic/-blocker-based treatment regimen: a subanalysis of the captopril prevention project. Diabetes Care. 2001;24(12):2091-6.

52. Wald DS, Law M, Morris JK, Bestwick JP, Wald NJ. Combination therapy versus monotherapy in reducing blood pressure: meta-analysis on 11,000 participants from 42 trials. Am J Med. 2009;122(3): 290-300.

53. Cholesterol Treatment Trialists' (CTT) Collaborators, Mihaylova B, Emberson J. The effects of lowering LDL cholesterol with statin therapy in people at low risk of vascular disease: meta-analysis of individual data from 27 randomised trials. Lancet. 2012;380(9841):581-90.
54. Fioretto P, Zambon A, Rossato M, Busetto L, Vettor R. SGLT2 inhibitors and the diabetic kidney. Diabetes Care. 2016;39(Suppl 2):S165-71.

55. Bae JH, Park E-G, Kim S, Kim SG, Hahn S, Kim NH. Effects of sodium-glucose cotransporter 2 inhibitors on renal outcomes in patients with type 2 diabetes: a systematic review and meta-analysis of randomized controlled trials. Sci Rep. 2019;9(1):13009.

56. Lo KB, Gul F, Ram P, et al. The effects of SGLT2 inhibitors on cardiovascular and renal outcomes in diabetic patients: a systematic review and metaanalysis. Cardiorenal Med. 2020;10(1):1-10.

57. Heerspink HJL, Stefánsson BV, Correa-Rotter R, et al. Dapagliflozin in patients with chronic kidney disease. N Engl J Med. 2020;383(15):1436-46.

58. Nam S, Chesla C, Stotts NA, Kroon L, Janson SL. Barriers to diabetes management: Patient and provider factors. Diabetes Res Clin Pract. 2011;93(1): $1-9$.

59. Mohammadi S. Knowledge, attitude and practices on diabetes among type 2 diabetic patients in Iran: a cross-sectional study. Sci J Public Health. 2015;3(4):520.

60. Estruch R, Ros E, Salas-Salvadó J, et al. Primary prevention of cardiovascular disease with a mediterranean diet supplemented with extra-virgin olive oil or nuts. N Engl J Med. 2018;378(25):e34.

61. Snorgaard O, Poulsen GM, Andersen HK, Astrup A. Systematic review and meta-analysis of dietary carbohydrate restriction in patients with type 2 diabetes. BMJ Open Diabetes Res Care. 2017;5(1): e000354.

62. Sluik D, Buijsse B, Muckelbauer R, et al. Physical activity and mortality in individuals with diabetes mellitus. Arch Intern Med. 2012;172(17):1285.

63. Vanhees L, Geladas N, Hansen D, et al. Importance of characteristics and modalities of physical activity and exercise in the management of cardiovascular health in individuals with cardiovascular risk factors: recommendations from the EACPR (Part II). Eur J Prev Cardiol. 2012;19(5):1005-33.

64. Tikkanen-Dolenc H, Wadén J, Forsblom C, et al. Physical activity reduces risk of premature mortality in patients with type 1 diabetes with and without kidney disease. Diabetes Care. 2017;40(12): 1727-32.

65. Pan A, Wang Y, Talaei M, Hu FB, Wu T. Relation of active, passive, and quitting smoking with incident type 2 diabetes: a systematic review and metaanalysis. Lancet Diabetes Endocrinol. 2015;3(12): 958-67. 
66. Cao S, Yang C, Gan Y, Lu Z. The health effects of passive smoking: an overview of systematic reviews based on observational epidemiological evidence. Li Y, editor. PLoS ONE. 2015;10(10):e0139907.

67. Britton J. Death, disease, and tobacco. Lancet. 2017;389(10082):1861-2.

68. Willi C, Bodenmann P, Ghali WA, Faris PD, Cornuz J. Active smoking and the risk of type 2 diabetes. JAMA. 2007;298(22):2654-64.

69. Mottillo S, Filion KB, Bélisle P, et al. Behavioural interventions for smoking cessation: a meta-analysis of randomized controlled trials. Eur Heart J. 2009;30(6):718-30.

70. Eisenberg MJ, Filion KB, Yavin D, et al. Pharmacotherapies for smoking cessation: a meta-analysis of randomized controlled trials. CMAJ. 2008;179(2):135-44.

71. Nagrebetsky A, Brettell R, Roberts N, Farmer A. Smoking cessation in adults with diabetes: a systematic review and meta-analysis of data from randomised controlled trials. BMJ Open. 2014;4(3): e004107.

72. Sherman JJ. The impact of smoking and quitting smoking on patients with diabetes. Diabetes Spectr. 2005;18(4):202-8.

73. Hokanson JM, Anderson RL, Hennrikus DJ, Lando HA, Kendall DM. Integrated tobacco cessation counseling in a diabetes self-management training program. Diabetes Educ. 2006;32(4):562-70.

74. Cockcroft DW, Gault H. Prediction of creatinine clearance from serum creatinine. Nephron. 1976;16(1):31-41.

75. Levey AS, Coresh J, Greene T, et al. Using standardized serum creatinine values in the modification of diet in renal disease study equation for estimating glomerular filtration rate. Ann Intern Med. 2006;145(4):247.

76. Levey AS, Stevens LA, Schmid CH, et al. A new equation to estimate glomerular filtration rate. Ann Intern Med. 2009;150(9):604. 